\title{
The Effect of Thickness and Type of Material on The Sheared Edge Characteristics of Keychain Cranioplasty Plate Blanking Product Using Eccentric Press Machine
}

\author{
Didin Zakariya Lubis*, Lea Rachmat Indrasepta, Redyarsa Dharma Bintara, \\ Rizky Ramadhan, Agung Budi Darmawan \\ Mechanical Engineering, State University of Malang, Jl. Semarang No.5, Malang, 65145, Indonesia \\ *Corresponding author:didin.zakariya.ft@um.ac.id
}

\begin{abstract}
Keychain cranioplasty plate product has the potential to be produced using the blanking process because it is faster, low-cost, and requires low-energy consumption compared to other mechanical operations. This research aimed to find the effect of material thickness and type on the sheared edge characteristics of keychain cranioplasty plate using the blanking process to meet the international health standard. Experimental research conducted using an eccentric press machine with 40 tons capacity. This research's test material parameters of titanium (Ti-6AL-4V) and stainless steel (SS-316L) were the $0.5 \mathrm{~mm}, 0.6 \mathrm{~mm}$, and $0.8 \mathrm{~mm}$ thickness with a maximum blanking velocity of $3000 \mathrm{~mm} / \mathrm{min}$ and $2.5 \%$ punch-die clearance. Then, the blanking products were observed using a digital microscope. The results showed that the optimum blanking product quality was found in the titanium (Ti-6AL-4V) and stainless steel (SS-316L) materials with $0.6 \mathrm{~mm}$ thickness because it had stable sheared edge characteristics in each zone compared to other variations.
\end{abstract}

Copyright (C) 2021. Journal of Mechanical Engineering Science and Technology.

Keywords: Blanking, clearance, keychain cranioplasty plate, punch, sheared edge characteristics

\section{Introduction}

Most medical devices are imported from abroad, with more than $90 \%$ are imported, and less than $10 \%$ are produced in the country [1]. The data stated that there is a high level of dependency on imported medical devices as high as the number of work accidents and traffic accidents in Indonesia. Each accident has the potential of fracture. Broken bones are expected to be in an anatomical position, i.e. the grafting is not only to connect but must connect in a straight position as the normal bone [2]. In current rapid technology development, many modern bone-implant methods are using a plate. Plate protects the fracture fragments so that the patient is allowed to move limitedly using the fractured organ [3]. One type of metal bone implant is a keychain cranioplasty plate.

Keychain cranioplasty plate is a mini plate in the form of a keychain to fixate the defect in the skull. It can be seen in figure 1 [4]. Mini plate produced using a press tool device such as an eccentric press machine with blanking and punching system. Press tool has several advantages to be used in the blanking process, among others, create mass products in uniform shape and size with more economical cost [5]. The resulted product from the blanking and punching should have smooth sheared edges to be applied. In the medical field, rough material surface quickens the immobilization and accelerate the growth of bacteria around the implant [6]. 


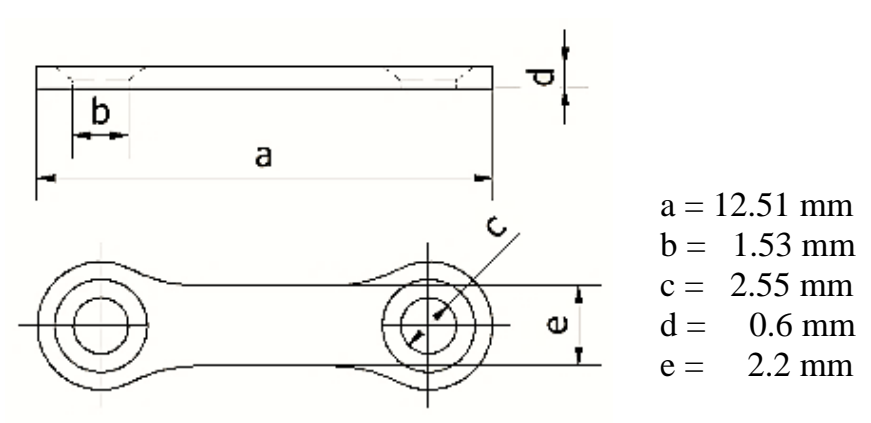

Fig. 1. Keychain cranioplasty plate

Previous research experimentally studied the effect of clearance and punch speed on the sheared edge results of punching process using a Micro Punch CNC machine in $500 \mu \mathrm{m}$ copper. The result showed the best clearance and rate was $2.5 \%$ and $2600 \mathrm{~mm} / \mathrm{min}$, respectively [7]. The burnish proportion during the blanking process with various materials also studied. Burnish is the result of the shear edge of the blanking process, burnish also expected to have a large proportion of the shear edge characteristics. In that research, the material with higher tensile strength had lower burnish proportion. The conclusion was that the material tensile strength was inversely proportional with the burnish proportion value [8].

However, further research on the proportion of burnish needed to be carried out on variations in material thickness to determine the level of variation in the burnish value. So that it will be known the variation of the best cutting speed parameters. This study aimed to obtain the best keychain cranioplasty plate quality based on burnish proportion.

\section{Material and Methods}

This study used an experimental study design, which is a study conducted by providing a particular treatment and then directly observing the results of these treatments. This research aimed to find the best product quality of sheared edge from blanking product using an eccentric press machine. Blanking of sheet metal is accomplished by a shearing action between two sharp cutting tool edges. The blanking tool consists of a moving upper part and a fixed lower part. It is essential to note the calculation and parameters in the blanking process to influence the produced outcome. Since the tip shape of the punch tool affects the sheared edge quality, this research used a flat tip with the distance between the punch-die (clearance) amounted to $2.5 \%$. The punch tool velocity was $3000 \mathrm{~mm} / \mathrm{min}$. The product shape was designed following the keychain cranioplasty plate (figure 1). The materials for this research were SS-316L and Ti-6Al-4V with $0.5 \mathrm{~mm}, 0.6 \mathrm{~mm}$, and $0.8 \mathrm{~mm}$ thickness. Table 1 explains its mechanical properties as referred to [9].

After the experimental step consisted of the blanking process using an eccentric press machine with the above variables and results, there needed calculations to find the product quality by observing the sheared edge characteristics. The calculation was conducted using Dino-Lite AM 3111T type digital microscope camera with 200x magnification, then processed in the Image-J software to obtain the shear zone from each zone. Figure 2 shows macro photograph of sections of a shear edge zone made with the use of a cylindrical punch. It shows the presence of different zones, namely rollover, sheared, fracture and burr zones. The magnification of the zone near the shear cut edge illustrates the degree of deformation 
of the microstructure. The minimum depth of the shear affected zone was approximately $75 \%$, which corresponds to more than one half of the sheet metal thickness.

Table 1. Mechanical properties of Titanium (Ti-6Al-4V) material

\begin{tabular}{lcc}
\hline Specification & Ti-6Al-4V & SS-316L \\
\hline Poisson's Ratio & 0.37 & 0.27 \\
Young modulus (GPa) & 119 & 190 \\
Density $\left(\mathrm{Mg} / \mathrm{m}^{3}\right)$ & 4.51 & 8.07 \\
Yield Strength $(\mathrm{MPa})$ & 925 & 290 \\
Tensile Strength $(\mathrm{MPa})$ & 1000 & 590 \\
\hline
\end{tabular}

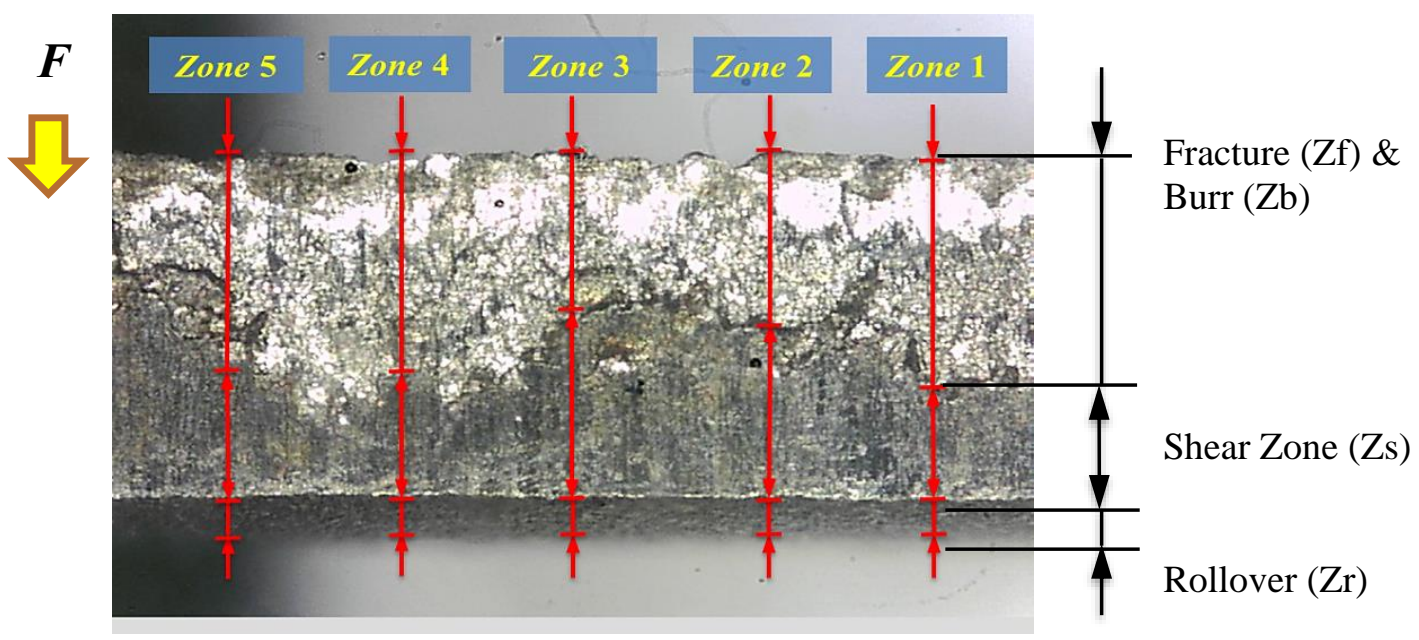

Fig. 2. Shear characteristics and observed zone of the blanking product

\section{Result and Discussions}

\section{A. The Effect of Material Type on the Sheared Edge Characteristics}

Table 2 presents the percentage results of the sheared edge characteristics from the blanking product of Ti-6Al-4V and SS-316L with $0.5 \mathrm{~mm}, 0.6 \mathrm{~mm}$, and $0.8 \mathrm{~mm}$ thickness. Based on Table 2, the rollover zone value in the SS-316L material is higher than Ti-6Al-4V material, and it occurs in all thickness variations. This happened because SS-316L material was more ductile than the brittle Ti-6Al-4V. Rollover zone $(\mathrm{Zr})$ is the initial plastic deformation zone. This corresponds to the depression made by the punch in the work prior to cutting, where initial plastic deformation occurred in work. It is followed the statement of [10] that the rollover zone is affected by clearance, material properties and tool wear.

The Young modulus value in a material which is a measure of the strength of the material also influences the rollover zone. Higher Young modulus value created larger deformation when given the force. The Ti-6Al-4V material had lower Young modulus 
material with $119 \mathrm{GPa}$ than SS-316L with $190 \mathrm{GPa}$ [11]. The study is supported by the occurrence that the Young modulus value of material influenced the rollover zone [12].

Table 2. Percentage results of the sheared edge characteristics based on the material type

\begin{tabular}{ccccccc}
\hline \multirow{2}{*}{$\begin{array}{c}\text { Material } \\
\text { thickness (mm) }\end{array}$} & \multicolumn{2}{c}{ Ti-6Al-4V } & \multicolumn{4}{c}{ SS-316L } \\
\cline { 2 - 7 } & Fracture (Zf) & $\begin{array}{c}\text { Shear zone } \\
(\mathrm{Zs})\end{array}$ & Rollover (Zr) & $\begin{array}{c}\text { Fracture (Zf) } \\
\text { and burr (Zb) }\end{array}$ & $\begin{array}{c}\text { Shear zone } \\
(\mathrm{Zs})\end{array}$ & $\begin{array}{c}\text { Rollover } \\
(\mathrm{Zr})\end{array}$ \\
\hline 0.5 & $96 \%$ & $41 \%$ & $21 \%$ & $42 \%$ & $71 \%$ & $38 \%$ \\
0.6 & $88 \%$ & $45 \%$ & $10 \%$ & $27 \%$ & $67 \%$ & $29 \%$ \\
0.8 & $62 \%$ & $43 \%$ & $13 \%$ & $20 \%$ & $52 \%$ & $17 \%$ \\
\hline
\end{tabular}

Shear zone (Zs) is the area before cracks. It occurs on a workpiece that has a smooth surface. Higher shear zone value increases the blanking product quality because of the smoother sheared edge. Based on table 2, the shear zone in SS-316L material is higher than Ti-6Al-4V material in all thickness variations. This was caused by higher dislocation strength and titanium atom density that made the deformation (changes in the composition of the atoms) which formed the area of the strain hardening became shorter. It made the ability of titanium atoms to slip more difficult. Dislocation (structural changes) caused strain (plastic deformation) and formed strain hardening and shear zone areas. The titanium crystal structure was hexagonal closest packed (HCP) with three denser slip systems. Hence, it had brittle material property compared to the stainless steel with its face-centered cubic (FCC) crystal structure and 12 slip systems that made it more ductile [9].

Fracture zone $(\mathrm{Zf})$ is a fractured area due to the downward punch with a relatively rough shear surface. Burr zone $(\mathrm{Zb})$ is the area of the sharp edge in the sheared edge because the workpiece experiences a strain during the cutting process or commonly referred to as burr. Based on table 2, the SS-316L has a lower fracture and burr zone compared to the Ti-6Al$4 \mathrm{~V}$ material in all thickness variations. It occurs due to the SS-316L material was more ductile than the brittle Ti-6Al-4V. The chemical composition greatly influences the ductility of the material [13]. The brittle fracture contours were uneven with a rough surface and where ductile fractures occur in the SS-316L material. The Ti-6Al-4V material had larger yield strength with $925 \mathrm{MPa}$ than the SS-316L with $290 \mathrm{MPa}$. According to Al-Momani dan Rawabdeh [14], this is influenced because the greater the yield value, the higher the material strain. So, the resulting fracture and burr zone is higher as well.

\section{B. The Effect of Material Thickness on the Sheared Edge Characteristics}

Material thickness greatly influences the shear zone values, as seen in Figure 3 and Figure 4. The SS-316L material reached the highest shear zone in the product with $0.5 \mathrm{~mm}$ thickness with a value of $71 \%$. Thicker material reduced the shear zone value. Thin metal has a smaller number of atomic grains along the direction of the shearing punch than in thicker metals, so the proportion of the shear zone is more dominant in thinner metals [15]. However, the Ti-6Al-4V material has an increase in the shear zone from $41 \%$ to $45 \%$ in products with $0.5 \mathrm{~mm}$ to $0.6 \mathrm{~mm}$ thickness, respectively. This followed the research that stated that thicker material reduced the shear zone value [16]. 


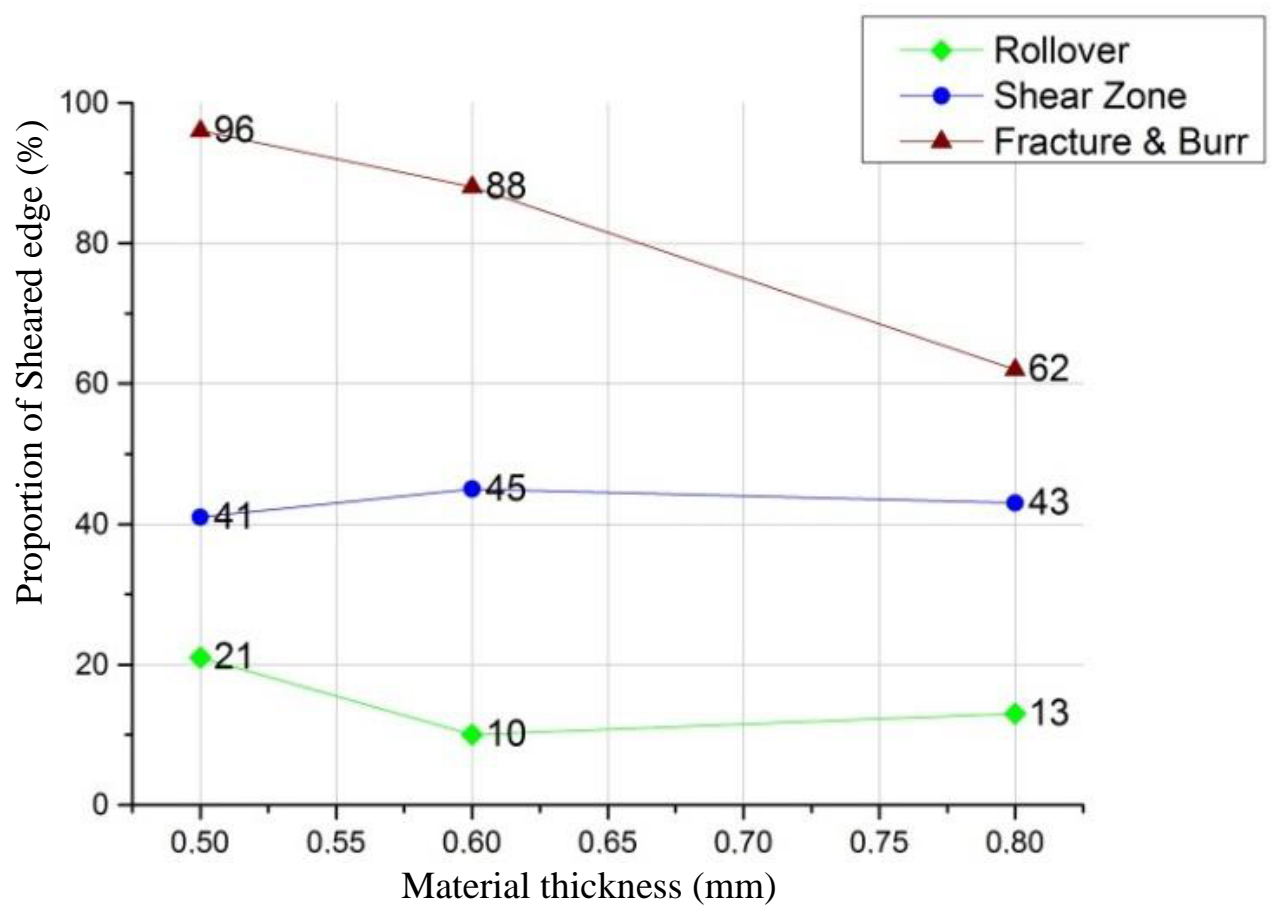

Fig. 3. Comparison graph of rollover zone (Zr), shear zone (Zs), and fracture and burr zone (Zf \& Zb) on Ti-6Al-4V material

Furthermore, the effect of material thickness on the fracture \& burr zone value is very influential, as seen in Figures 3 and 4 for both SS-316L and Ti-6AL-4V materials use. The overall graph concludes that the thicker the material, the lower the fracture value $\&$ burr zone. This result is in accordance with the other research results in which thin material formed small fracture and burr zone value [11].

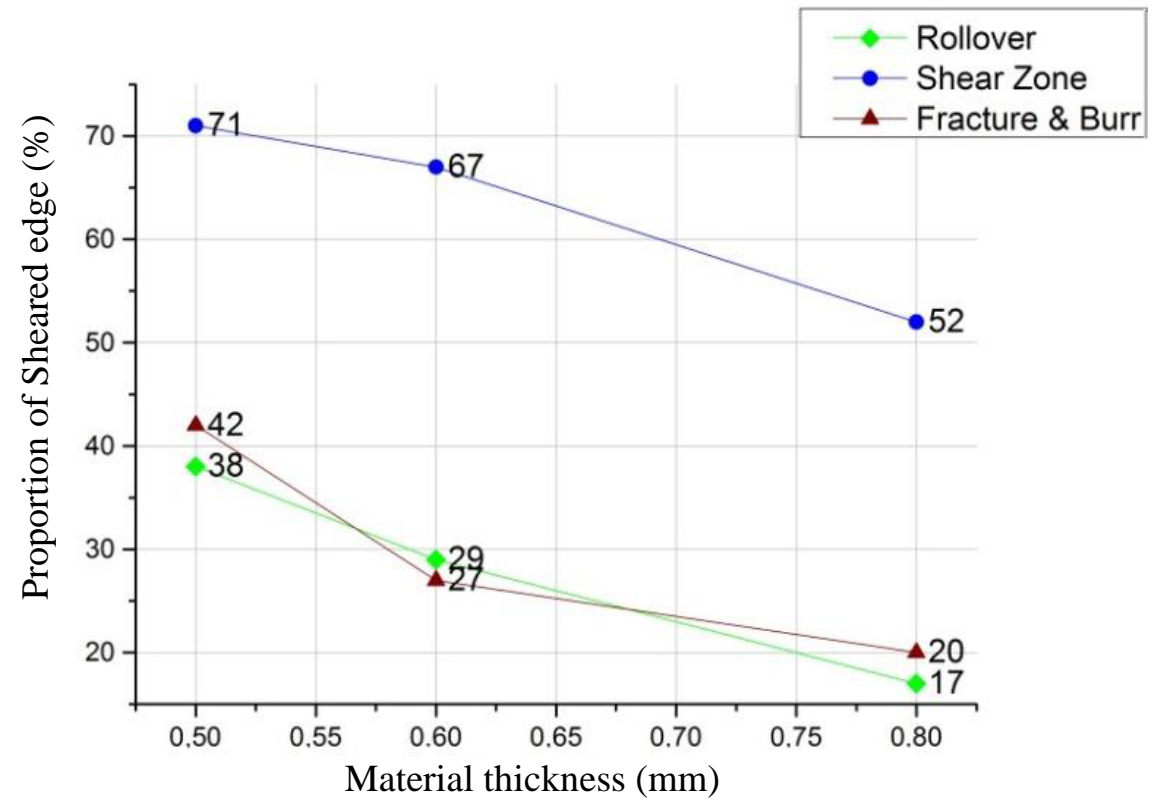

Fig. 4. Comparison graph of rollover zone (Zr), shear zone (Zs), and fracture and burr zone (Zf \& Zb) on SS-316L material 


\section{Conclusion}

Material type greatly influences the sheared edge characteristics in each zone because each material had different properties. The best material type for blanking product was SS$316 \mathrm{~L}$ because it had the highest shear zone with the percentage of $71 \%, 67 \%$, and $52 \%$ for each thickness, compared to the Ti-6Al-4V with the percentage of $41 \%, 45 \%$, and $43 \%$ for each thickness variation. Material thickness in the blanking process greatly affected the sheared edge characteristics from each zone. Thicker material reduced the values of the rollover, shear zone, fracture and burr. This was because thinner metals had a smaller number of atomic grains along the direction of the shearing punch than thicker metals, and thicker material had a higher volume so that the proportion of the cutting area was more dominant in thinner metals. The high-quality parameter for blanking products of Ti-6Al-4V and SS-316L materials was found in the products with $0.6 \mathrm{~mm}$ thickness because they had stable sheared edge characteristics in each zone compared to other thickness variations. The decent product has a high shear zone value. Higher shear zone increased the product quality because of the smoother sheared edge, but it should also be followed with low rollover, fracture, and burr zone values.

\section{Acknowledgment}

This research and Work facilities was supported by PNBP FT UM grant and Mechanical Engineering Department State University of Malang. Gratefully acknowledgment.

\section{References}

[1] Kemenkes RI, "Center for Data and Information on Indonesia's Health Profile 2016", InfoDATIN, 2017.

[2] Mahmoud, D., Al-Rubaie, K. S., Elbestawi, M. A., "The Influence of Selective Laser Melting Defects on the Fatigue Properties of Ti6Al4V Porosity Graded Gyroids for Bone Implants", International Journal of Mechanical Sciences, vol. 193, 106180, 2021.

[3] Singh, G., Sharma, N., Kumar, D., Hegabd, H., "Design, Development and Tribological Characterization of Ti-6Al-4V/hydroxyapatite Composite for Bioimplant Applications", Materials Chemistry and Physics, vol 243, 122662, 2020.

[4] Festas, A.J, Pereira, R. B., Ramos, A., and Davim, J. P., "A Study of the Effect of Conventional Drilling and Helical Milling in Surface Quality in Titanium Ti-6Al-4V and Ti-6AL-7Nb Alloys for Medical Applications", Arabian Journal for Science and Engineering, vol. 46, pp 2361-2369, 2021.

[5] Bubphachot B., "Microstructure Affecting Cutting Quality in Fine Blanking Process Microstructure Affecting Cutting Quality in Fine Blanking Process", American J. of Engineering and Applied Sciences, vol. 2 (4), pp. 665-668, 2009.

[6] Arifvianto, B., Suyitno, and Mahardika, M, "Effect of Sandblasting and Surface Mechanical Attrition Treatment on Surface Roughness, Wettability, and Microhardness Distribution of AISI 316L", Key Engineering Materials, vol. 462-463, pp. 738-743, 2011.

[7] Lubis, D. Z. and Ristiawan, I., "Blanking Clearance and Punch Velocity Effects on The Sheared Edge Characteristic in Micro-Blanking of Commercially Pure Copper Sheet", Journal of Mechanical Engineering Science and Technology, vol. 1(1), pp. 
53-60, 2017.

[8] Levy, B. S. and Van Tyne, C. J., "Review of The Shearing Process for Sheet Steels and Its Effect on Sheared-Edge Stretching", Journal of Materials Engineering and Performance, vol. 21(7), pp. 1205-1213, 2012.

[9] Kalpakjian, S. and Schmid, S. R., "Manufacturing Engineering and Technology in SI Units", Manufacturing Engineering and Technology, pp. 502 (2009).

[10] Grünbaum, A., "Reply to Symposium on the Grünbaum Debate", Psychoanal, Dialogues, vol. 10(2), pp. 335-342, 2000.

[11] Ristiawan, I., and Mahardika, M., "Effect Of Clearance and Punch Speed on The Cutting Surface Quality Results of a Brass Blanking on The Micropunch CNC Machine", AIP Conference Proceedings, vol. 20054, pp. 1-10, 2017.

[12] Engin, K. E., and Eyercioglu, O., "Investigation of the Process Parameters on The Blanking of AISI 304 Stainless Steel by Using Finite Element Method", Journal of Mechanics Engineering and Automation, vol. 6, pp. 356-363, 2016.

[13] Liu, Y., Wang, C., Guo, B., Shan, D., and Zhang, M., "Softening Effect of Ultrasonic Vibration on Micro-blanking Deformation Behaviour of Titanium Foil", Micro \& Nano Letters, vol. 12, pp. 808-812, 2017.

[14] Aravind, U., Chakkingal, U., and Venugopal, P., "A Review of Fine Blanking: Influence of Die Design and Process Parameters on Edge Quality", Journal of Materials Engineering and Performance, vol. 30, pp. 1-32, 2021.

[15] Majerníková, J. and Spišák, E., "Punch-Die Gap Effect on Blanked Edge in Fine Blanking of Low-Carbon, Micro-Alloyed and High-Strength Steels", Applied Mechanics and Materials, vol. 474, pp. 279-284, 2014.

[16] Kulkarni, D., Adhikraoshinde, R., and Badgujar, J. P., "Clearance Optimization of Blanking Process", International Journal of Scientific \& Engineering Research, vol. 6(12), pp. 178-191, 2015. 